\title{
Correlation Between Urinary Vasopressin and Water Content of Food in the Bottlenose Dolphin (Tursiops truncatus)
}

\author{
Cristina Ballarin, Livio Corain, Antonella Peruffo, Bruno Cozzi*
}

Department of Experimental Veterinary Science, University of Padova, Viale dell'Università, 16, 35020 Legnaro Agripolis (PD), Italy

\begin{abstract}
Marine mammals, including the bottlenose dolphin Tursiops truncatus, must rely on the water content of their food to achieve water balance. We have investigated the endocrine role of the antidiuretic hormone (vasopressin) in relation to food intake and water conservation. A series of seven bottlenose dolphins, maintained in a controlled environment, were sampled for blood and urine before and after the meals. Blood vasopressin levels were around $1.1 \mathrm{pg} / \mathrm{ml}$. In urine, the hormone is one hundred fold more concentrated than in blood. Therefore we considered the urinary vasopressin content in relation to food intake. A direct relationship was detected among food intake, vasopressin and $\mathrm{NaCl}$ urinary concentrations. Our data indicate that urinary vasopressin levels increase after the meal and correspond to a rise in $\mathrm{NaCl}$ levels, a sign of urine concentration indicating that the effect of vasopressin in this species is aimed at curtailing the dispersion of food-derived water.
\end{abstract}

Keywords: Vasopressin, water balance, urine, bottlenose dolphin, Tursiops truncatus.

\section{INTRODUCTION}

Life in a hyperosmotic environment requires specific evolutionary adaptations, including morphological and physiological changes in the kidneys and in all the body systems involved in the maintenance of water homeostasis. The metabolic cost of drinking sea water exceeds the benefits, and different aquatic mammals, i.e. pinnipeds, manatees, sea-otters, polar bears and cetaceans, use specific strategies to achieve a balanced osmolarity (for review see [1]). Some of these mammals possess the theorical capacity to make their urine more concentrated than sea water [2-4]. However, despite their reniculate structure and increased medullary thickness, the kidneys of marine mammals are poor urine concentrators $[2,5]$ and only pinnipeds and sea-otters actually manage to reach urinary $\mathrm{Na}^{+}$and $\mathrm{Cl}^{-}$concentrations similar to those of sea water [6]. Urine osmolality values reported in the literature for the bottlenose dolphin Tursiops truncatus $\left(1815\right.$ mosmol ${ }^{-1}$, [7]) are higher than in humans (1400 mosmol $\left.{ }^{-1},[8]\right)$ but closer to those described in the $\operatorname{dog}(1800$ mosmol 1-1, [9]).

There is general consensus that for cetaceans life in seawater requires an active process to maintain internal fluid composition, and that sea-otters are unique among marine mammals in drinking sea water $[1,10]$. Therefore mammals fully living in sea water rely mostly on food for their required water intake.

The vasopressin (also known as antidiuretic hormone), synthesized by the supraoptic and paraventricular nuclei of

*Address correspondence to this author at the Department of Experimental Veterinary Science, University of Padova, Viale dell'Università, 16, 35020 Legnaro - Agripolis (PD), Italy; Tel : + 39.049.8272626;

Fax :+39.049.8272669; E-mail : bruno.cozzi@unipd.it the hypothalamus and released in the capillaries of the neurohypophysis, contributes to a number of physiological functions, including water reabsorption in the distal tubules and collecting ducts of the kidney. Vasopressin secretion is influenced by the water content of the body and by other factors, including stress and possibly also by the time of the day (at least in humans). Attempts at measuring plasma vasopressin in dolphins encountered several technical problems, in addition to its very low levels [10].

When the study of vasopressin required non-invasive methods, as in the case of human newborns, vasopressin concentration has been studied in the urine as an alternative to blood [11]. In other mammals, such as dogs, the rates of vasopressin clearance are linearely correlated with vasopressin plasma levels up to $100 \mu / \mathrm{kg} / \mathrm{min}$ infusion rates [12].

The present work deals with the osmoregulatory effects of vasopressin in marine mammals and aims at determining for the first time the urine concentration of vasopressin sampled from trained captive bottlenose dolphins. Acquired data were analyzed in relation to food and water intake and urinary $\mathrm{NaCl}$ concentration. We also compared the levels of vasopressin in urine and plasma. The existence of possible significant variations in vasopressin urinary concentration in relation to food intake was checked by appropriate statistical analysis. This paper analyzes the hypothesis that dolphins secrete vasopressin in response to food intake to exploit their principal source of water.

\section{MATERIALS AND METHODS}

\section{Animals}

A series of seven healthy female bottlenose dolphins of different ages were included in this study. They were individually identified by letters: A (6 years old), B (9 years 
old), C (6 years old), D (9 years old), E (28 years), F (38 years), G (28 years). Animals were housed at Zoomarine Portugal (a marine mammal theme Park) and trained under operant-conditioning techniques to perform the collection of urine and blood for routine medical analyses.

The dolphins were grouped according to age into young ( $\mathrm{Y}$ group, up to 9 years) and old ( $\mathrm{O}$ group, older than 28 years). See Table 1.

All animals were fed 4-5 times a day with a mix of fish (Clupea harengus, Scomber japonicus, Sprattus sprattus, Trachurus trachurus, Micromesistius poutassou, Mallotus villosus) and squid (Loligo vulgaris). All animals were fed at approximately $4-5 \%$ of their body weight per day. The quantity of water assumed with food $\left(\mathrm{H}_{2} \mathrm{O}\right)$ was determined by adding the humidity of the separate components fed each time. Dolphins were sometimes administered water by gavage. Forced water administration (hydration) of a maximum amount of $1000 \mathrm{ml}$ has therefore been considered a statistical variable.

The daily feeding schedule remained approx. constant for the duration of the experiment. In contrast, both urine and blood sampling were performed only when the animals were willing to cooperate. Urine and blood were sampled from all the animals within 75 minutes after food administration.

\section{Sample Collection}

\section{Urine}

Urine samples (20-25 ml /animal) were collected under training; the animal was trained to remain 'belly up', the collection site was then dried and disinfected. The animal was trained to respond on a cue and when the urine started to flow it was collected by a sterile syringe. A total of 120 urine samples were collected from the seven dolphins. $\mathrm{NaCl}$ concentration in urine was determined in all the samples while for technical reasons the vasopressin urinary concentration was measured on 59 out of the 120 samples. All samples were measured in duplicate. The number of $\mathrm{NaCl}$ and vasopressin samples obtained for each subject are summarized in Table $\mathbf{1}$.

\begin{tabular}{|c|c|c|c|}
\hline \multirow{3}{*}{ Y group } & A & 19 & 6 \\
\hline & $\mathrm{C}$ & 14 & 8 \\
\hline & $\mathrm{D}$ & 17 & 9 \\
\hline \multirow{3}{*}{ O group } & $\mathrm{E}$ & 20 & 14 \\
\hline & $\mathrm{F}$ & 24 & 6 \\
\hline & G & 7 & 6 \\
\hline \multicolumn{2}{|c|}{ Old group total } & 51 & 26 \\
\hline
\end{tabular}

\section{Blood}

Blood samples were collected in five animals (A, B, D, $E, F)$ from the central vein on the ventral surface of the caudal fluke, directly into chilled heparinized tubes. Plasma was separated by centrifugation and stored at $-20^{\circ} \mathrm{C}$ until assayed for RIA analysis of vasopressin.

\section{Radioimmunoassay}

Vasopressin was assayed by a commercially available radioimmunoassay (RIA) kit designed for use in human urine (Euro-Diagnostica Vasopressin Kit, IBL Hamburg, Germany). The sensitivity of the kit, defined as 3 standard deviations change from zero calibrator, was $0.5 \mathrm{pmol} / \mathrm{l}$. The RIA kit was validated before use with dolphin urine and blood. Dose-response curves and increasing concentrations of vasopressin standard added to urine were parallel to the standard curve. Plasma samples were extracted with ethanol following the kit manufacturers' instructions, while urinary vasopressin was measured directly in non-extracted urine diluted 1:5 in assay buffer in a total volume of $0.3 \mathrm{ml}$.

\section{$\mathrm{NaCl}$ and Creatinine Concentrations}

Urinary $\mathrm{Na}^{+}$and creatinine (creat) concentrations were evaluated using an automated analyzer system BM Hitachi 911 (ROCHE, Basel, Switzerland) automated biochemical analyzer.

\section{Statistics}

For estimation and statistical inference we adopted the linear model within the framework of analysis of covariance [13]. Since not only food administration but some other possible relevant features could potentially affect the $\mathrm{NaCl} / \mathrm{creat}$ and $\mathrm{ADH} /$ creat concentrations during the sampling process as well, our statistical analysis tried to take that into consideration. Some of these factors were related to some individual aspects such as age. Moreover, hydratation has been also considered in the linear model as potential confounding agent. Note that, since we sampled from several subjects during the time, the linear model is potentially affected by a within subject time effect, so that the error independence assumption could be violated. Hence, in order to check this

\section{Table 1. Number of Samples for $\mathrm{NaCl}$ and $\mathrm{ADH}$ by Age and Subject}


possible bias, we performed a goodness of fit [14] within subject residual analysis where we found any residual autocorrelation. Finally, the inspection of the residual normal probability plot and the application of Anderson-Darling Normality Test [15] confirmed that the normality assumption of random errors is consistent.

All statistical analysis have been performed by Minitab® statistical software (Minitab Inc., State College, PA, U.S.A.), release 13.20. Significance was defined as $p<0.05$.

\section{Ethics of Experimentation}

All samples were collected using routine husbandry training and obtained during periodical medical check-ups from unrestrained animals. All procedures described were performed in accordance with the Animal Welfare Act for the care of Marine Mammals and the European Communities Council directive (86/609/EEC) concerning animal welfare. Furthermore, Zoomarine Portugal is a Zoological Garden sensu directive 1999/22/CE, as well as a member of both EAZA (European Association of Zoos and Aquaria) and AMMPA (Alliance of Marine Mammal Parks and Aquariums), complying with their requirements in terms of animal husbandry.

\section{RESULTS}

A specific radioimmunoassay for vasopressin has been validated in dolphin urine and plasma.

The mean concentration of vasopressin in plasma was $1.106 \pm 0.116 \mathrm{pg} / \mathrm{ml}$ (mean \pm s.e.m.). Urinary vasopressin concentrations were much higher than in blood, with a mean value of $108.8 \pm 10.6 \mathrm{pg} / \mathrm{ml}$ (value ranged between 6.4 and $367.5 \mathrm{pg} / \mathrm{ml})$.

Plasma levels were close to the detection limit of the RIA assay and since we found a direct relationship between vasopressin concentration in urine and in plasma (estimated regression equation is $\mathrm{U}_{\text {vasopressin }}=-6.2+151 \mathrm{P}_{\text {vasopressin }}$, were $\mathrm{R}^{2}=72.3 \%$, see Fig. 1) the analysis subsequently focused on urinary vasopressin concentration.

The urinary vasopressin and $\mathrm{NaCl}$ concentrations were corrected for urinary creatinine to adjust for differences in urine flow. Table $\mathbf{2}$ summarizes statistics of the physiological parameters considered in our study, specifically urinary vasopressin/creat and $\mathrm{NaCl} /$ creat ratios and water content of food.

Table 3 displays the estimated Pearson correlation coefficients [13] and related $p$-values for pairs of the three variables of interest. Results suggest a positive linear relationship between all pairs of variables, confirmed by significant related $p$-values.

We considered the linear model as a tool for investigating and estimating a possible significant variation in $\mathrm{NaCl} / \mathrm{creat}$ and $\mathrm{ADH} /$ creat concentration due to water administration via food. Results in Table 4 suggest that $\mathrm{H}_{2} \mathrm{O}$ has a significant and positive effect on both $\mathrm{NaCl} /$ creat and Vasopressin/creat. This effect is not simply linear as revealed by the significance the $\mathrm{H}_{2} \mathrm{O}$ quadratic effect $\left(\mathrm{H}_{2} \mathrm{O}\right)^{2}$, hence we decided to include this effect in the statistical model (Figs. 2, 3). Con-

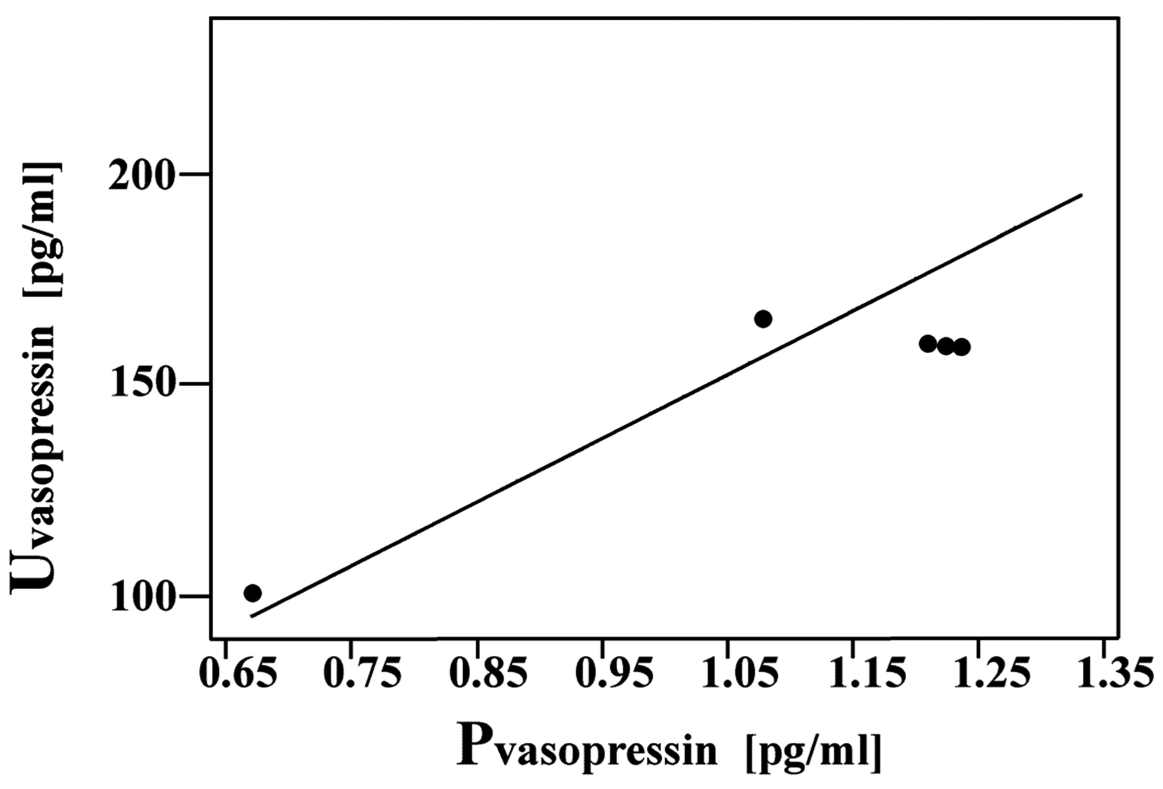

Fig. (1). Relationship between urinary and plasmatic vasopressin concentrations [pg/ml].

Table 2. Summary statistics for $\mathrm{H}_{2} \mathrm{O}, \mathrm{NaCl} / \mathrm{Creat}$ and $\mathrm{ADH} / \mathrm{Creat}$

\begin{tabular}{|c|c|c|c|c|c|c|c|c|c|}
\hline Variable & $\begin{array}{c}\text { No. of } \\
\text { samples }\end{array}$ & Mean & Median & $\begin{array}{l}\text { Standard } \\
\text { Deviation }\end{array}$ & SE of Mean & Minimum & Maximum & $\begin{array}{l}\text { Q1 (First } \\
\text { Quartile) }\end{array}$ & $\begin{array}{c}\text { Q3 (Third } \\
\text { Quartile) }\end{array}$ \\
\hline $\mathrm{H}_{2} \mathrm{O}[\mathrm{ml}]$ & 120 & 3462 & 3640 & 2433 & 222 & 0 & 10075 & 1079 & 5145 \\
\hline $\mathrm{NaCl} / \mathrm{Creat}$ & 120 & 21.8 & 19.6 & 12.9 & 1.2 & 1.5 & 58.6 & 11.4 & 30.9 \\
\hline $\mathrm{ADH} / \mathrm{Creat}\left(* 10^{-6}\right)$ & 59 & 11.3 & 8.4 & 10.0 & 1.3 & 1.2 & 55.8 & 4.21 & 15.8 \\
\hline
\end{tabular}


cerning possible confounding effects of age and hydratation, we did not observe any significant effect by hydration and by age on vasopressin/creat, while there is a significant effect of age on $\mathrm{NaCl} /$ creat. $(p=0.005)$.

Table 3. Estimated Pearson Correlation Coefficients (and Related $p$-Values) for Water, $\mathrm{NaCl} / \mathrm{Creat}$ and ADH/Creat

\begin{tabular}{|c|c|c|}
\hline & water & NaCl/Creat \\
\hline \hline $\mathrm{NaCl} /$ Creat & 0.602 & \\
\hline & $(p=0.000)$ & \\
\hline & & 0.480 \\
\hline $\mathrm{ADH} /$ Creat & 0.548 & $(p=0.000)$ \\
\hline & $(p=0.003)$ & \\
\hline
\end{tabular}

\section{DISCUSSION}

Early literature indicated that even Delphinids which prey mostly on hyposmotic teleosts do not gain sufficient advantage in water conservation and considered the yield of water from the metabolism of proteins and fats apparently insufficient for the needs of the animal [6]. In the last two decades several studies helped solving questions relative to the water homeostasis of marine mammals (for review see Ortiz [1]). However the relationships between vasopressin secretion and water intake remained partly unsolved in cetaceans.

Our RIA analysis on vasopressin plasma levels yielded values that were lower than those previously described in the literature for the same species [16]. However, this latter study deals with wild dolphins momentarily restrained for sampling.

To overcome the problem of low plasma concentration of vasopressin, we tested the same hormone in the urine. The concentration of vasopressin in the blood of dolphins is in fact very low, around the detection limit of the RIA kit, while its concentration in urine is much higher, as demonstrated in other mammals [17]. The results we obtained indeed suggest that the measurement of the urinary concentration of vasopressin is a reliable method of assessing plasma vasopressin, as already shown in man [18]. We estimated the relationship between urinary and plasmatic vasopressin concentrations as $\mathrm{U}_{\text {vasopressin }}=146 \mathrm{P}_{\text {vasopressin }}$ were intercept can be considered zero as its $p$ value is 0.903 . Our results show a relationship between plasma and urine concentrations and for this reason we considered urinary vasopressin concentration for our analysis.

Vasopressin and $\mathrm{NaCl}$ urinary concentration are dependent on the urinary volume nevertheless, as it was not possible, for technical reasons, to measure the total urinary volume we have corrected urinary data for urinary creatinine.

Statistical analysis indicates that vasopressin levels in the urine (and possibly in the blood) are correlated to water intake through food and result in higher salt $(\mathrm{NaCl})$ concentrations in the urine, a measure of urine concentration and hence of water reabsorption and conservation (Table 3 ). Results in Table 4 and Fig. (3) (showing the relationship between $\mathrm{NaCl} / \mathrm{creat}$ and water content of food) further indirectly suggest a possible relationship between food administration and vasopressin concentration. $\mathrm{NaCl} / \mathrm{creat}$ and $\mathrm{ADH} / \mathrm{creat}$ were found to be significantly and positively correlated (Table 3) in the 60 samples with both values. When the analysis was performed on 120 urine samples, we found a positive quadratic relationship between $\mathrm{H} 2 \mathrm{O}$ and $\mathrm{NaCl} /$ creat (Fig. 3), thus indirectly confirming the relationship between $\mathrm{H}_{2} \mathrm{O}$ and vasopressin by estimating the proxy relationship $\mathrm{NaCl}-\mathrm{H}_{2} \mathrm{O}$.

Figs. (2) and (3) suggest that an increase in food, and hence water intake (up to 5 liters), leads to a rise in vasopressin concentration.

Greater water intake (up to 10 liters) is followed by a decreased vasopressin concentration. A possible explanation for the change of pattern above a certain quantity of food water content may be based on the assumption that when hydration exceeds a defined level, vasopressin is no longer required to retain liquids. Furthermore, a relationship between vasopressin concentration and food intake, as we report here, may also explain the lower vasopressin values described in wild dolphins [16], where the state of nutrition was obviously impossible to evaluate.

We are aware of the fact that some dolphins were hydrated with 500-1000 ml of water. Nevertheless nonsignificant $p$-values in Table 4 show that this treatment did not affect vasopressin/creat and/or $\mathrm{NaCl} /$ creat concentrations, because the effect of water (contained in the food) becomes evident only at higher quantities. This specific result may be important when forced hydration is evaluated to treat kidney stones, also taking into account the effects of the increase in volume of the stomach complex within the limited space of the abdominal cavity. Modifications of the diet (with a higher percentage of squids) may be more effective.

Table 4. Linear Model Results for ADH/Creat and NaCl/Creat versus Linear and Quadratic Effect of Water, Age and Hydration

\begin{tabular}{|c|c|c|c|c|c|c|}
\hline \multirow{2}{*}{$\begin{array}{c}\text { Source of } \\
\text { Variation }\end{array}$} & \multicolumn{3}{|c|}{ ADH/Creat } & \multicolumn{3}{c|}{ NaCl/Creat } \\
\cline { 2 - 7 } & Estimated Effect & F-Value & $p$-Value & Estimated Effect & F-Value & $p$-Value \\
\hline \hline $\mathrm{H}_{2} \mathrm{O}$ & 0.0044 & 12.75 & 0.001 & 0.0062 & $-4.1^{*} 10^{-6}$ & 11.52 \\
\hline$\left(\mathrm{H}_{2} \mathrm{O}\right)^{2}$ & $-4.8^{*} 10^{-6}$ & 4.61 & 0.036 & 2.95 & 0.000 \\
\hline Age & 0.376 & 0.09 & 0.760 & 0.17 & 0.005 \\
\hline Hydration & -1.889 & 2.92 & 0.093 & 0.148 & 0.02 \\
\hline
\end{tabular}




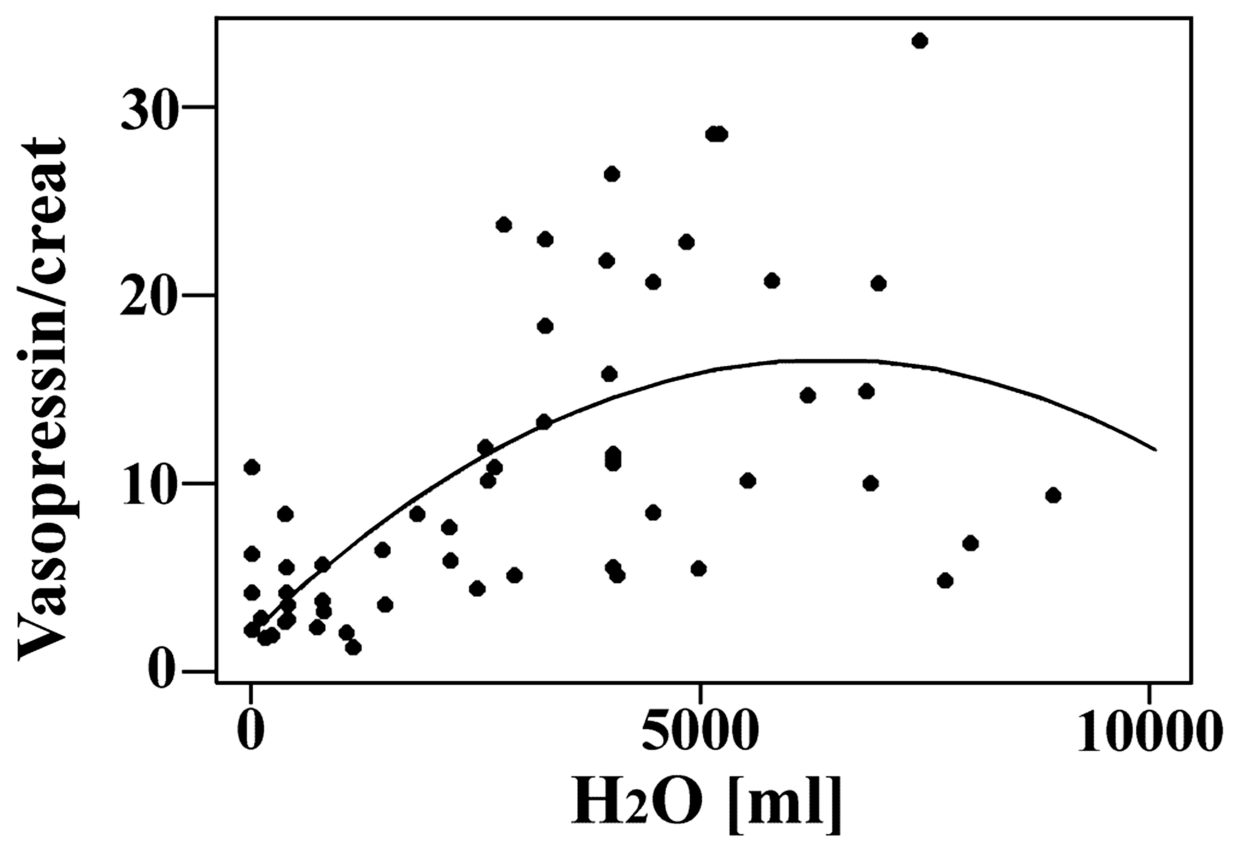

Fig. (2). Quadratic regression model for water content of food $\left(\mathrm{ml} \mathrm{of} \mathrm{H}_{2} \mathrm{O}\right)$ and urinary vasopressin concentration normalized for creatinine.

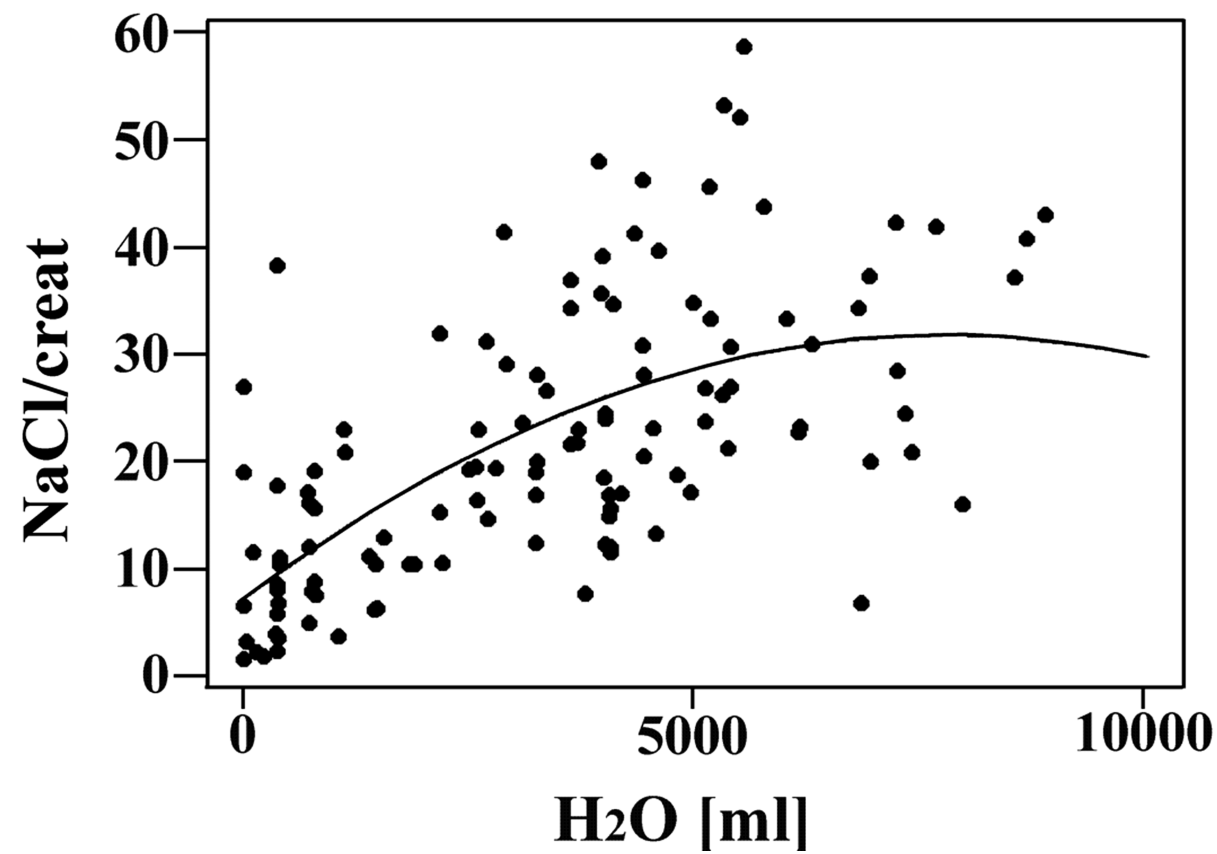

Fig. (3). Quadratic regression model for water content of food $\left(\mathrm{ml} \mathrm{of} \mathrm{H}_{2} \mathrm{O}\right)$ and urinary $\mathrm{NaCl}$ concentration normalized for creatinine.

Circadian rhythmicity of vasopressin secretion possibly played a role on the release of vasopressin. Studies on the circadian rhythm of vasopressin secretion are numerous and well known in humans, where plasma vasopressin concentration shows a maximum peaks at midnight and fell to a minimum in the late afternoon [19]. However, studies on circadian variation of vasopressin secretion in the rat and other mammals are controversial [20]. We have no way to investigate further the possibility that an endogenous clock mechanism regulates or influences vasopressin secretion in these mammals, given the limitations imposed on feeding and sampling times, plus the necessity to avoid any night sampling because of technical difficulties, stress and ethical reasons. Interestingly, hyperbaric studies in man evidenced that circadian rhythmicity of vasopressin production is disrupted at depth and diuresis enhanced [21]. Whether this may apply also to marine mammals remains unsolved. We cannot also exclude that the physiological actions of other hormones (angiotensins, ANP and aldosterone), involved in mammalian osmoregulation, may be heavily influenced by the peculiar pattern of hydration through food typical of marine mammals. Future studies may help us to better define these complex interactions in dolphins.

The values that we report for vasopressin concentration in the urine may be considered as a standard for a cohort of bottlenose dolphins maintained within a controlled environment and fed with a balanced diet that includes also 
the highly humid and hyperosmotic Loligo vulgaris. The same conditions may not apply to populations in the wild, where food intake may vary greatly and fasting may happen.

\section{ACKNOWLEDGMENTS}

Some of the samplings of blood and urine from the captive bottlenose dolphins were taken during a research project involving two Ph.D. theses discussed at the University of Padua by Drs. Alessandro Bortolotto and Lara Papini; the contribution of the latter is here gratefully acknowledged. The authors express their gratitude to the management and staff of Zoomarine Portugal for the helpful cooperation and particularly to Ana Salbany, Karina Massei and Elena Guglielmi. The authors gratefully acknowledge the valuable technical assistance of $\mathrm{Mr}$. Giovanni Caporale and $\mathrm{Mr}$. Tommaso Brogin of the Department of Experimental Science of the University of Padua.

\section{REFERENCES}

[1] Ortiz RM. Osmoregulation in marine mammals. J Exp Biol 2001; 204: 1831-44.

[2] Bester MN. The functional morphology of the kidney of the Cape fur seal, Arctocephalus pusillus (Schreber). Modoqua Ser II 1975; 4: 69-92.

[3] Costa DP. Energy, nitrogen, electrolyte flux and sea water drinking in the sea otter Enhydra lutris. Physiol Zool 1982; 55: 35-44.

[4] Maluf NSR. Renal anatomy of the manatee, Trichechus manatus (Linnaeus). Am J Anat 1989; 184: 269-86.

[5] Vardy PH, Bryden MM. The kidney of Leptonychotes weddelli (Pinnipedia: Phocidae) with some observations on the kidneys of two other Southern phocid seals. J Morphol 1981; 167: 13-34.

[6] Gaskin DE. Kidney and water metabolism. In: Bryden MM, Harrison S, Eds. Research on dolphins. Oxford UK: Clarendon press 1986; pp. 129-49.
[7] Malvin RL, Rayner M. Renal function and blood chemistry in Cetacea. Am J Physiol 1968; 214: 187-91.

[8] Vander AJ Ed. Renal Physiology. $5^{\text {th }}$ ed. New York: McGraw-Hill Inc; 1995.

[9] Di Bartola SP, Chew DJ, Jacobs G. Quantitative urinanalysis including 24-hour protein excretion in the dog. J Am Vet Med Assoc 1980; 16: 537-46.

[10] Malvin RL, Bonjour, JP, Ridgway S. Antidiuretic hormone levels in some cetaceans. Proc Soc Expl Biol Med 1971;136:1203-05

[11] Wiriyathian S, Rosenfeld CR, Arant BSJr, Porter JC, Faucher DJ, Engle WD. Urinary arginine vasopressin: pattern of excretion in the neonatal period. Pediatr Res 1986;20:103-8

[12] Sondeen JL, Claybaugh JR. Clearance and urinary excretion of vasopressin in conscious dogs. Am J Physiol 1989; 256:R291-98

[13] Daniel WW. Biostatistics: a foundation for analysis in the health Sciences. $8^{\text {th }}$ ed. Wiley Series in Probability and Statistics, New York: John Wiley \& Son Inc., 2004.

[14] Draper NR, Smith H. Applied Regression Analysis. Wiley Series in Probability and Statistics, New York: John Wiley \& Son Inc 1998.

[15] Thode HC. Testing for Normality. Statistics, Textbooks and Monographs 164, New York: Marcel Dekker 2002.

[16] Ortiz R M, Worthy GAJ. Effects of capture on adrenal steroid and vasopressin concentrations in free-ranging bottlenose doplphins (Tursiops truncatus). Comp Biochem Physiol A Mol Integr Physiol 2000; 125: 317-24

[17] Miller M, Moses A M. Radioimmunoassay of urinary antidiuretic hormone in man: response to water load and dehydration in normal subject. J Clin Endocrinol Metab 1972; 34:537-45

[18] Moses AM, Steciak E. Urinary and metabolic clearances of arginine vasopressin in normal subjects. Am J Physiol 1986;25: 365-70

[19] Forsling ML, Montgomery H, Halpin D, Windle RJ, Treacher DF. Daily patterns of secretion of neurohypophysial hormones in man: Effect of age. Exp Physiol 1998; 83:409-18.

[20] Wells T, Windle RJ, Peysner K, Forsling ML. Inter-colony variation in fluid balance and its relationship to vasopressin secretion in male Sprague-Dawley rats. Lab Anim 1993; 27: 40-46

[21] Takeuchi H, Mohri M, Shiraki K, Lin YC, Claybaugh JR, Hong SK. Diurnal renal responses in man to water loading at sea level and 31 atm abs. Undersea Hyperb Med 1995; 22:61-71

(C) Ballarin et al.: Licensee Bentham Open.

This is an open access article licensed under the terms of the Creative Commons Attribution Non-Commercial License (http://creativecommons.org/licenses/by-nc/3.0/) which permits unrestricted, non-commercial use, distribution and reproduction in any medium, provided the work is properly cited. 